\title{
An Analysis of Earning the Market Share Vs Buying the Market Share
}

\author{
Sonika Kanojia \\ Assistant Professor, University School of Business-Industry Collaborated Programs, Chandigarh University, Mohali-140413 \\ Punjab, India
}

Article History: Received: 11 January 2021; Accepted: 27 February 2021; Published online: 5 April 2021

\begin{abstract}
The current market is going through lot of changes. The companies in all the industries are making lot of exciting strategies to compete with each other and secure a big portion in the overall market share. The two primary strategies used by the companies to acquire the market share are buying the market share and earning the market share.

To observe the consumer behavior that which one of the aforementioned strategies affect the customers the most, we conducted an analysis by way of this research paper. An intensive literature review was done apart from going through the audited records of many companies to know about their marketing strategies. Best possible research methodology was used to accomplish the desired objectives. The study was conducted in Chandigarh University, Mohali (Punjab), which happens to be more like a Cosmopolitan. The required data was collected using a structured questionnaire; presented to the respondents post pretesting. The results showed that customer finds the steps used in the buying of market share to be very fascinating and attractive. Though, these strategies works well in short term but in the long term, it's the Earning the market share strategy (that includes quality of the product and creation of Brand equity) which decides the customer's tastes.
\end{abstract}

Keywords: Competition, Strategies, Formulation, Buyer Persona

\section{Introduction}

The customer serves as the only factor in any industry. If the customer can be convinced to buy any product, the sales goes up and the companies acquire market share. On contrary, the consumer gets demotivated to buy the product of the rival's product and market share of the competitors goes down. This shows that rise in the market share of one company results in the loss of market share in its rival's products and vice versa. This creates a cut throat competition between all the companies within one industry. As a result, all the companies come up with many interesting and well planned strategies for enhancing their respective product's market share. In earning the market share the companies primarily focuses on the quality and quantity of their products, the customer feedbacks and the after sales services. But companies want to increase their instant share, they plan to provide lot of offers in the forms of cash-backs, discounts and freebies which leads to instant gain in market share and can be defined as buying the market share.

The humanity has developed civilizations based on transactions. Started with the barter system, which was later replaced by money, the earning of the market share strategy (namely quality and quantity) of the product and services involved in any transaction has remained as the key factor. If the quality is superior then the consumer will buy it at (comparatively) higher prices also. While any compromise in the quality may results in the reduction of the demand for that commodity. In quantity, the increase may serve as a motivation for the customers; but the same may be considered only when the quality is not compromised. This proves that companies focuses more on the quality of the product while also keeping the quantity as a determining factor.

There is no record related to the origin of the Buying the Market share strategy (which majorly revolves around better offer and deals in form of cash backs, discounts and freebies). But it is assumed that giving the discounts started in the beginning of the civilization when the humans started doing transactions based on the negotiations related to buying more in quantity while paying less than what was offered by the seller. The concept of cash backs is a very new thing. This started in the second half of the 20th century when new modes of payments started coming like credit cards and semi wallets. Here the customer has to pay the entire amount at one time and then receives a part of the total payment back in their account or wallet, as the case maybe. Similarly, freebies or the product given as free apart from the original or the base product are the one for which the customer do not have to pay anything over the M.R.P. of the base product but still enjoys the benefits of their utility. This must be understood that though it is presented by the company to be a free product to its customers but still the cost of that freebie is covered by the company under the M.R.P. of the base product while also maintaining an overall profit margin.

\section{Literature Review}

Durre and Giot (2007) use integration framework for testing the presence of a long-term Contemporary relationship between earnings and found that long-term movements in the share market are mainly driven by the earnings, while changes in the yields on long-term government bond have a short-term impact on stock prices movements and don't appear to have a significant long-term impact on long run market price of stocks. 
Malakar and Gupta (2002) studied and discovered that earning market share has significant impact on market price.

Fisher and Statman (2000) investigated and found that P/E ratio are not good indicators of future Stock returns over the short period of time, but forecasting power of $\mathrm{P} / \mathrm{E}$ is better used to estimate stock returns over the longer period of time, while in more extensive way Rapach and Wohar (2005) Reported the presence of little evidence of correlation between $\mathrm{P} / \mathrm{E}$ ratio and future stock price changes in the short term, but correlation that is found is high over longer time perspective. Market price of a given share is required to calculateits $\mathrm{P} / \mathrm{E}$ ratio, but the P/E ratio of a company offers better insight into the growth potential of share in the terms of market price.

Nabhi Kumar Jain (1992) advised the investors to buy shares of a growing company. By buyingshares, diversifies in a number of growth companies operating in a different but equally fast growingsector of the economy.

John Consler (2011) the object of this paper was to make the correlation of relative intensity of working income and profit in the expectation of profits. 1902 profits paying firms were broke down for study reason. Quarterly detail information has been taken for the year 2002 to 2006. Income per share is appeared to deliver a superior fit than gaining per share dependent on chose demonstrate fit criteria. Creator likewise recommended that financial specialists and examiners anticipate profits as a piece of their stock valuation work.

\section{Objective}

To determine the performance of the marketing strategies by analyzing the comparison between buying the market share and earning the market share.

As the research work progresses, following benefits shall be derived out of it:

(i) The critical comparison and examination between the two extremely different buying strategies of the companies, namely:

(a) Buying the Market Share; and

(b) Earning the Market Share.

(ii) The interpretation of the buyer persona as to how the companies should deal with them.

(iii) The analysis of the customer taste that brand equity (made by better quality and effective quantity) is the more significant factor for them or the variables like discount, cashbacks or freebies.

\section{Research Methodology}

Area of Study: Chandigarh University, which itself serves as a mini-cosmopolitan, with students coming from all diverse backgrounds and part of the country and from foreign nations, has been selected as the area of study. This will help in getting the data from all the major customer groups and income groups.

Market Selected for the Analysis: We have selected the retail market for conducting this research and analysis.

Population: All those who falls within the definition of the buyer:

- Be it a Consumer; or

- A Customer.

Sampling Unit: Existing Buyer and Customers

Research Design Description: The research design is descriptive in nature; Descriptive Research Design is a scientific method which includes the analysis and describing the behavior of the respondents without influencing their response or feedback at all.

Sample Size: 195 (This sample size was determined statistically and it came out to be 195 with the confidence level of 5\%).

Sampling Technique Used: Convenience sampling; as the respondents were the existing customers or consumers in the market mainly those who were easily approachable were interviewed using a structured questionnaire.

Type of Data

- Collected: Primary Data

- Used: Primary Data

Data Collection Tools: Structured Questionnaire

Statistical Tools Used: The various Statistical tools used are:

- Analysis

- Graphs

- Tables

- Charts

5. Data Analysis

Specific Data Collected from the Respondents

1. Channel preferred for shopping 
Which channel do you prefer for shopping?

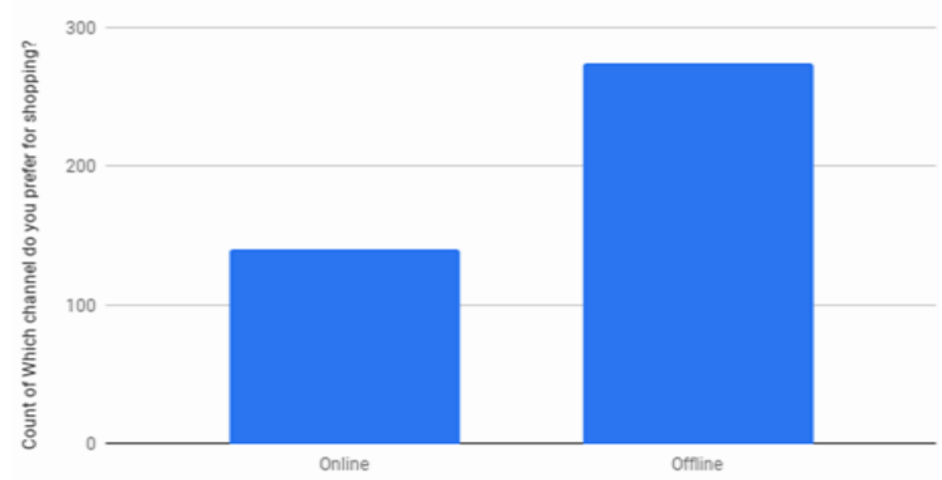

Fig.1: Preferred Shopping Channel

The above chart explains that only $33.8 \%$ of the respondents prefer online channel for shopping whereas the other $66.2 \%$ admitted the offline shopping channel as a preferred choice. This helps in realizing that people still prefer that conventional shopping channel which is mostly based on earning the market share.

2. A store is offering no discount on cash payment but good discount on payment by card/online. Would you still pay cash?
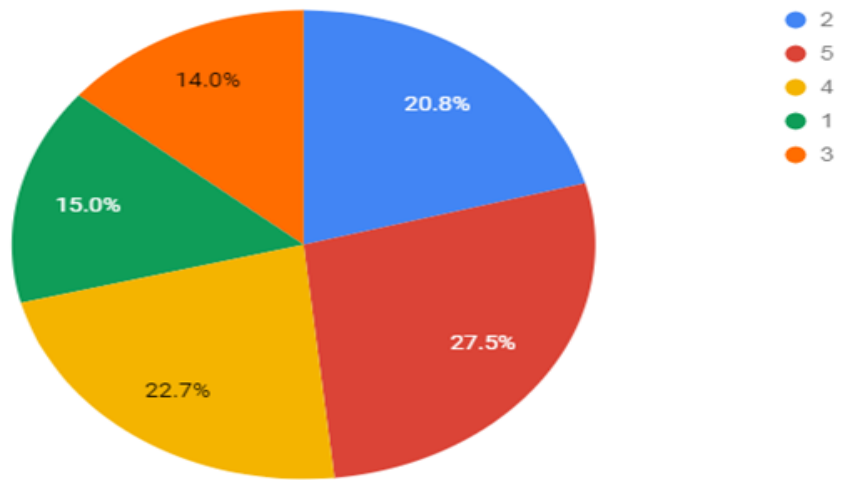

Fig.2: Would you still pay in cash?

The aforementioned pie chart shows that $22.7 \%$ and $27.5 \%$ of them are disagreeing and strongly disagreeing respectively to pay in cash. While $20.8 \%$ and $15 \%$ of them admitted to agree and strongly agree respectively to pay in cash avoiding any kind of discount. This clearly implies that just to have more savings the respondents may get more inclined towards claiming the discount by way of making payments other than cash.

3. You are at a market place for buying a mobile and the same feature mobile of that other brand are available online with some discount. Will you still buy it from shop?

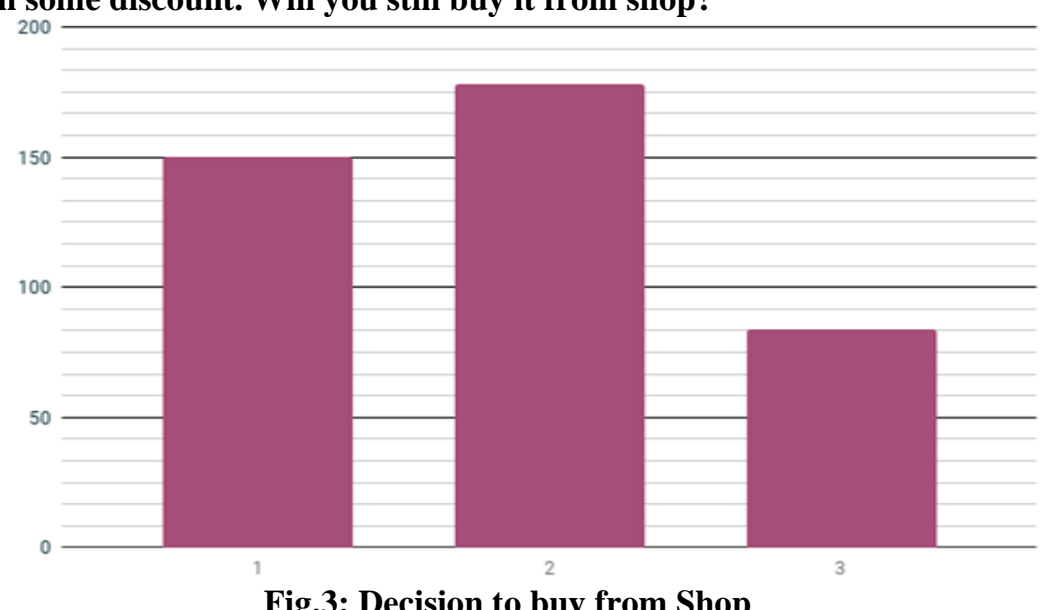

Fig.3: Decision to buy from Shop

The above stated bar diagram clearly reveals that the $43.2 \%$ of the respondents, who denied shopping from the store, are not brand loyal but just prefer to save more money and still get the desired features by whichever means is possible. While $36.4 \%$ of the respondents consented to still buy from the shop and the rest $20.4 \%$ remained confused to make a concrete decision as to buy from shop or buy at less price.

4. Your favorite brand product is available at the store without discount, but a new product at good discount. Will you shift to new product? 


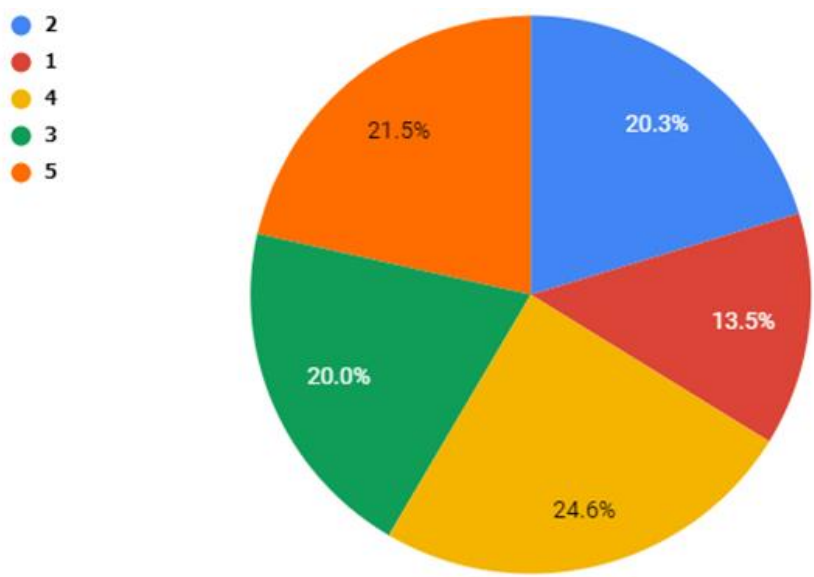

Fig.4: Decision to shift to the new product

The above pie chart reveals that $13.5 \%, 20.3 \%, 20 \%, 24.6 \%$ and $21.5 \%$ of the respondents strongly agree, agree, can't say, disagree and strongly disagree respectively to make a decision of buying a new product. Here, it is evident that more than $50 \%$ of the respondents are not in a mood of shifting to a new product and only $33 \%$ consumers who wants to shift to a new product for the sake of discounts while the other $20 \%$ is without in opinion.

5. Online shopping provides more discounts but minimum 2 days to deliver the product. Offline/physical stores provide fewer discounts but the product is delivered instantly. Where would you buy the product?
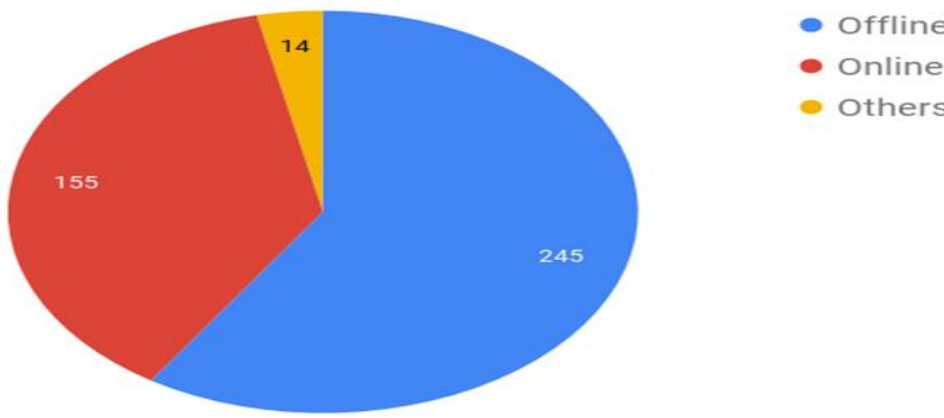

Fig.5: Where to buy the product

The above given pie chart signifies that for today's customer the delivery time constitutes an important factor in shopping. Irrespective of the offers and discount, the respondents clearly expressed their desire to receive the product at the earliest, no matter whether they buy online or offline.

6. Which factor affects your buying decision the most?

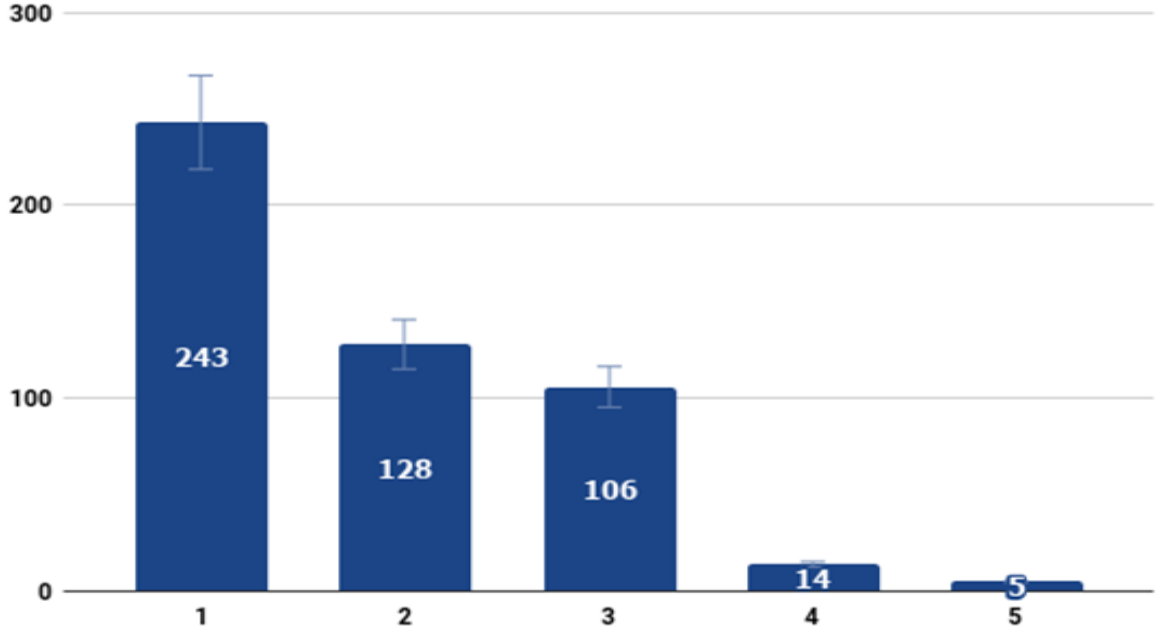

Fig. 6: Factors Affecting the Buying Decision

The above given bar diagram is an evidence of the fact that $58 \%$ (i.e. 243) of the respondents, which means majority of them, are more inclined towards quality of the product while shopping. But still some $30.9 \%$ (i.e. 128) of the respondents consider quantity of the product as the primary factor during shopping. 25\% (i.e. 106) of the respondents believe in the brand value while a hardly $4.5 \%$ (i.e. 19) respondents showed their views of looking at discount offered on any product or any other factor (except the ones mentioned above) as the primary factor they consider while shopping. 


\section{Which Factor do you consider while shopping the Product?}

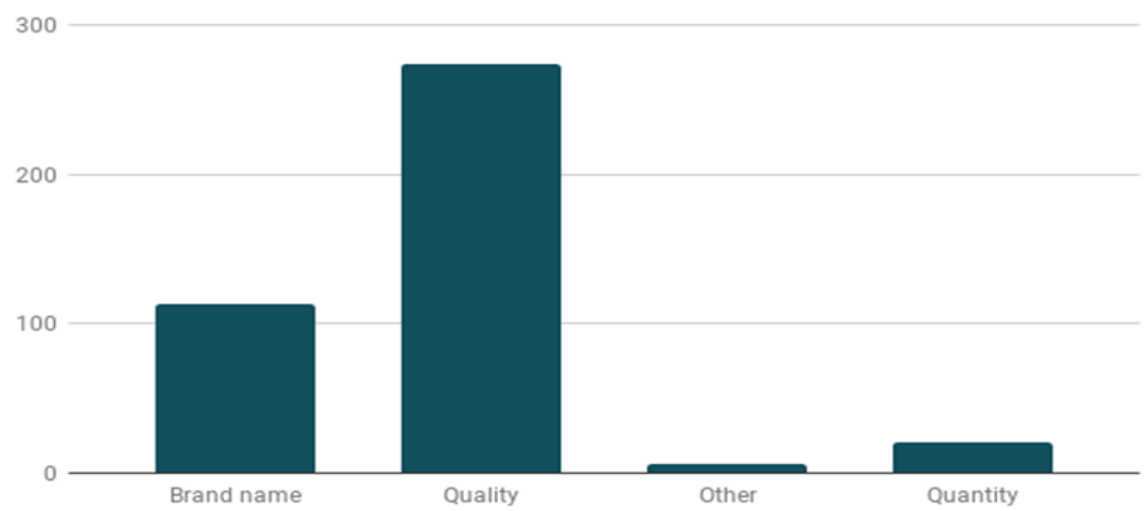

Fig. 8: Factor(s) considered while shopping

As per the above given bar diagram, 66\% (i.e. 274) respondents have voted the quality of the product as the factor considered the most while shopping. This is a clear majority of the total number of respondents and we can say that quality is the factor considered with utmost importance above all other factors. Interestingly, 27.29\% (i.e. 113) respondents still believe the brand value as the most important factor. However, this also a known fact that the brand name of any product is established with years of consistency in providing good quality product; which means that again the factor that comes into the picture is in terms of the quality. But still some $6.5 \%$ (i.e. 27) respondents are amazed by the quantity of the product. But their tiny numbers are of least significance on the whole statistics.

\section{Which of the below aspects catches your attention more?}

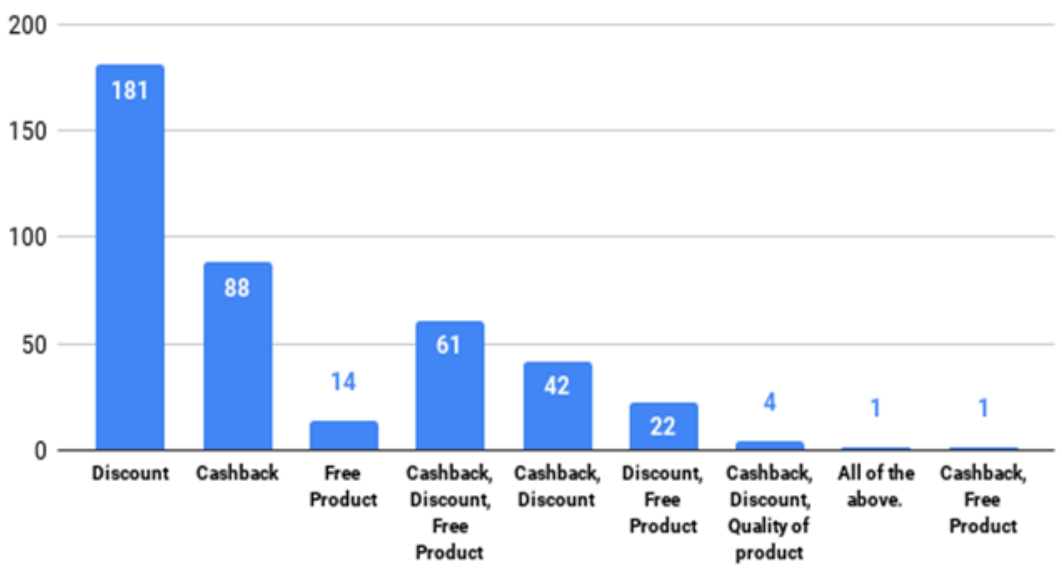

Fig. 9: Bar diagram showing the aspects that catches the attention more

The above bar diagram shows that $43.71 \%$ (i.e. 181) of the respondents agreed that discounts solely catches their attention meaning that the customers may want better quality but a discount given somewhere may become a possible factor for shopping. This can be understood with a small example that, if one shop is giving good discount on the same product which is sold without any discount at another store, then the customers are likely to shop at the store which is giving that discounts.

The same thing goes for other set of responses made by the respondents.

Like in the case of the combination of cash back, discounts and free products, with a total respondents vote of $14.73 \%$ (i.e. 61), we can say that the respondents are equally cautious about all these criteria or parameters while shopping. Similar interpretations can be drawn about cash back and discount combinations or discount and free product combination. This makes us conclude that discount on the product is the only factor which remains fixed for majority of the respondents while all the other factors remains variable.

\section{Finding and Conclusion}

The study period has been challenging time for the pharmaceutical industry in general and Sun Pharmaceuticals in particular. Year 2020 has been challenging for the businesses at the all the parts of the world. The study has analysed the movement of key financial indicators of Sun Pharmaceuticals. It has been found that there is been severe variability in the key financial indicators like Total Income, EBIT Margin \%, PAT Margin\% and VaR.

The effect of pandemic in the pharma business can be easily seen in the various results which have been obtained during the process of the study. The Value at Risk with $95 \%$ confidence level shows the improvement trend showing the improving level of risk.

With this we have come to the conclusion of the research paper. In the course of our research and analysis, we found multiple new fact and figures. Processing these data helped us in formulating some findings and recommendations. They have been briefly discussed below: 
a. As per the company's perspective, this research revealed that quality of the product serves as the biggest driving force for the customers irrespective of what buying the market share strategy the company uses.

b. The factors of 'Earning the Market Share Strategy' are fixed factors and the factors of 'Buying the Market Share Strategy' are mostly the variable factors that keep on changing as per the market situation and condition.

c. The study states the most of the respondents are aware of most of the buying the market share strategies that are being used by the companies: be it the cash backs, discounts or freebies.

d. Though the majority of buying the market share offers comes from e-commerce channel, still the offline channel has remained an important medium for most of the respondents even though the offers comparatively might be less.

e. The study also depicts that large numbers of respondents majorly recognizes the brand value of any product only after years of consistency in the quality of the product.

f. The customers getting attracted by buying the market share strategies mainly gets more influenced by discounts on any product in comparison of the other factors related to the same marketing strategy.

g. If the fixed factors (i.e. the quality and quantity of the product which belongs to the earning the market share) remains the same, then the customer may immediately get attracted towards or shift to the rival's product for better offer or deals in form of cash backs, discount or freebies.

\section{Recommendations}

1. The market remains very volatile in terms of responding to the buying the market share strategy. But the same also harvests very favorable results in the short term. Therefore, it is advisable to be very careful in using this strategy.

2. The customers are more focused on quality of the product which comes under earning the market strategy, so no matter what buying the market share strategy the company use but they should not compromise in terms of the quality of the product.

3. Well established companies keep on introducing some innovation to attract their customer as keep their market share growing. On the other hand the companies who loose customers, tend to give good offers and block the purchase of customers for a longer period.

4. Rather of simply giving lot of unnecessary offers to attract customers, the startups (which have high fundings) should instead put more focus and resources on R \& D of their product and services. This will help improve the quality of the product and serve as the most judicious technique to use the fund on expansion.

5. The advantages of earning the market share helps in the creation of the brand value. Therfore, companies should try to carve their own niche, in order to groom the brand equity.

6. As per our findings, we would like to suggest that the real power of customer loyalty is earned only when the company uses a mixed-blend or a combination of both the Earning the market share strategy as well as Buying the market share strategy. It is then only the customer will have the highest level of utility from a product and will get inclined to a particular brand.

\section{Limitations of the Study}

This study has been conducted by analysing the respondents confined in a particular location of Chandigarh University sitauted in Mohali (Punjab). Hence the results and conclusions may not be treated as representative of the entire Republic of India. The possible factors behind any discrepancy can be:

- Some of the respondents may have given biased responses to the questionnaire.

- Since we had structured questionnaire with a set of options only, so there could be chances of some other response that the respondent wants to give but the same was not available.

- We also had limited time to perform the analysis, research work and response evaluation. Therefore, chances do exist that we might have missed few facts.

- Being the students of Chandigarh University, most of the respondents belong to the age group of 18 to 30 years. Therefore, some aspects related to the buying decion of those from above 30 years of age might not have been materialised in this analysis.

\section{References}

1. Robert D. and Daniel N.E. Nolle , Journal of Money, Credit and Banking, Vol. 28, No. 4, Part, (Nov., 1996), pp. 622-636.

2. https://hbr.org/1975/01/market-share-a-key-to-profitability

3. https://www.investopedia.com/ask/answers/031815/what-strategies-do-companies-employ-increasemarket-share.asp

4. https://hbr.org/1975/01/market-share-a-key-to-profitability

5. https://hbr.org/1975/11/strategies-for-high-market-share-companies

6. https://www.investopedia.com/ask/answers/031815/what-strategies-do-companies-employ-increasemarket-share.asp 